\title{
Early hyperoxemia is associated with lower adjusted mortality after severe trauma: results from a French registry
}

Josefine S. Baekgaard ${ }^{1,2^{*}}$ D, Paer-Selim Abback ${ }^{3}$, Marouane Boubaya ${ }^{4}$, Jean-Denis Moyer ${ }^{3}$, Delphine Garrigue ${ }^{5}$, Mathieu Raux ${ }^{6}$, Benoit Champigneulle ${ }^{7}$, Guillaume Dubreuil ${ }^{8}$, Julien Pottecher ${ }^{9}$, Philippe Laitselart ${ }^{10}$, Fleur Laloum ${ }^{11}$, Coralie Bloch-Queyrat ${ }^{4}$, Frédéric Adnet ${ }^{1}$, Catherine Paugam-Burtz ${ }^{3}$ and Traumabase ${ }^{\circledast}$ Study Group

\begin{abstract}
Background: Hyperoxemia has been associated with increased mortality in critically ill patients, but little is known about its effect in trauma patients. The objective of this study was to assess the association between early hyperoxemia and in-hospital mortality after severe trauma. We hypothesized that a $\mathrm{PaO}_{2} \geq 150 \mathrm{mmHg}$ on admission was associated with increased in-hospital mortality.

Methods: Using data issued from a multicenter prospective trauma registry in France, we included trauma patients managed by the emergency medical services between May 2016 and March 2019 and admitted to a level I trauma center. Early hyperoxemia was defined as an arterial oxygen tension $\left(\mathrm{PaO}_{2}\right)$ above $150 \mathrm{mmHg}$ measured on hospital admission. In-hospital mortality was compared between normoxemic $\left(150>\mathrm{PaO}_{2} \geq 60 \mathrm{mmHg}\right)$ and hyperoxemic patients using a propensity-score model with predetermined variables (gender, age, prehospital heart rate and systolic blood pressure, temperature, hemoglobin and arterial lactate, use of mechanical ventilation, presence of traumatic brain injury (TBI), initial Glasgow Coma Scale score, Injury Severity Score (ISS), American Society of Anesthesiologists physical health class $>1$, and presence of hemorrhagic shock).

Results: A total of 5912 patients were analyzed. The median age was 39 [26-55] years and 78\% were male. More than half (53\%) of the patients had an ISS above 15, and 32\% had traumatic brain injury. On univariate analysis, the in-hospital mortality was higher in hyperoxemic patients compared to normoxemic patients (12\% versus $9 \%, p<$ 0.0001). However, after propensity score matching, we found a significantly lower in-hospital mortality in hyperoxemic patients compared to normoxemic patients (OR 0.59 [0.50-0.70], $p<0.0001$ ).

Conclusion: In this large observational study, early hyperoxemia in trauma patients was associated with reduced adjusted in-hospital mortality. This result contrasts the unadjusted in-hospital mortality as well as numerous other findings reported in acutely and critically ill patients. The study calls for a randomized clinical trial to further investigate this association.
\end{abstract}

Keywords: Hyperoxemia, Hyperoxia, Trauma, Critical care, Oxygen

\footnotetext{
* Correspondence: josefinebeakgaard@me.com

'Urgences et Samu 93, AP-HP, Avicenne Hospital, Inserm U942, 93000

Bobigny, France

${ }^{2}$ Department of Anesthesia, Section 4231, Centre of Head and Orthopedics,

Rigshospitalet, University of Copenhagen, Juliane Maries Vej 10, DK-2100

Copenhagen, Denmark

Full list of author information is available at the end of the article
}

\section{$\triangle B M C$}

(c) The Author(s). 2020 Open Access This article is licensed under a Creative Commons Attribution 4.0 International License, which permits use, sharing, adaptation, distribution and reproduction in any medium or format, as long as you give appropriate credit to the original author(s) and the source, provide a link to the Creative Commons licence, and indicate if changes were made. The images or other third party material in this article are included in the article's Creative Commons licence, unless indicated otherwise in a credit line to the material. If material is not included in the article's Creative Commons licence and your intended use is not permitted by statutory regulation or exceeds the permitted use, you will need to obtain permission directly from the copyright holder. To view a copy of this licence, visit http://creativecommons.org/licenses/by/4.0/ The Creative Commons Public Domain Dedication waiver (http://creativecommons.org/publicdomain/zero/1.0/) applies to the data made available in this article, unless otherwise stated in a credit line to the data. 


\section{Introduction}

Each year, 5.8 million people die as result of trauma making it the leading cause of death for individuals below 45 years of age [1]. Furthermore, trauma constitutes a major economic burden, as trauma-related costs were estimated to $\$ 671$ billion in 2013 in the USA alone [2]. Efforts to lower the mortality and morbidity following trauma are therefore of highest importance. The prehospital management of severe trauma patients requires a rapid approach during which it is recommended to provide supplemental oxygen to both treat and prevent hypoxemia [3, 4]. As a result, high fractions of inspired oxygen $\left(\mathrm{FiO}_{2}\right)$ are commonly administered during this initial phase and may result in hyperoxemia on hospital admission. However, exposure to high oxygen levels, even during a short period of time, has been associated with cerebral and coronary vasoconstriction, deleterious effects on lung function, and increased production of reactive oxygen species [5-10].

In a large meta-analysis on randomized controlled trials (RCT), which compared liberal and conservative oxygenation administration in acutely ill patients, the relative risk of in-hospital mortality was increased amongst patients treated with a liberal oxygen approach compared to a conservative oxygen approach [11]. A recent systematic review also investigated the relationship between hyperoxemia and mortality in critically ill patients and found a similar association [12].

Despite an increasing awareness of the potentially deleterious effects of elevated arterial oxygen partial pressure $\left(\mathrm{PaO}_{2}\right)$ in acutely ill patients [13], the prevalence of hyperoxemia in the emergency department (ED) and the intensive care unit (ICU) remains high [14-16]. Furthermore, a recent cohort study found a link between early hyperoxemia in the ED and mortality [14].

However, the association between hyperoxemia and mortality in the trauma population remains controversial. In one RCT, authors found no effect of exposure to different levels of $\mathrm{FiO}_{2}$ on mortality amongst patients suffering from traumatic brain injury (TBI) [17]. A recent observational study on 24,148 mechanically ventilated patients with TBI found no effects of hyperoxemia on mortality either [18].

Taken as a whole, knowledge on the effects of hyperoxemia in trauma patients is sparse and the evidence for systematic oxygen therapy in these patients is thus inadequate, especially in the pre-hospital setting [19].

The primary objective of this study was to assess the association between elevated $\mathrm{PaO}_{2}$ on hospital admission and in-hospital mortality in level I trauma centers. We hypothesized that a $\mathrm{PaO}_{2} \geq 150 \mathrm{mmHg}$ on admission was associated with increased in-hospital mortality.

\section{Methods}

\section{Study design}

This was an observational study using a multicenter, prospective trauma registry in France, the TraumaBase ${ }^{\circ}$. The TraumaBase consecutively collects data on trauma patients from 15 trauma centers in France. A central administrator monitors the data and the TraumaBase is approved by the Institutional Review Board as well as the National Commission on Informatics and Liberties. The study is reported in accordance with the STROBE guidelines [20].

\section{Setting}

Between May 2016 and March 2019, data collected from the 14 level 1 trauma centers was reviewed (one center had not yet included patients). As previously described [21], the French EMS system consists of two levels of triage that will trigger a paramedic-staffed ambulance or a physician-staffed mobile ICU (Service Mobile d'Urgence et de Réanimation (SMUR)). In case of major trauma, the SMUR will always be activated and accompany the patient to a specialized trauma center.

\section{Participants}

Trauma patients above 17 years of age with a $\mathrm{PaO}_{2}$ measured and registered in the TraumaBase ${ }^{\oplus}$ registry were included. Hypoxemic patients $\left(\mathrm{PaO}_{2}<60 \mathrm{mmHg}\right.$ on arrival) and patients withdrawn from life-sustaining therapy were excluded. Baseline characteristics on hypoxemic patients can be found in the Additional file 1.

\section{Variables}

The following variables were extracted from the database: age (years), gender, American Society of Anesthesiologists (ASA) score, initial Glasgow Coma Scale (GCS) score, pre-hospital systolic blood pressure and heart rate, mechanism and site of injury, volume fluid replacement (mL of colloids and/or crystalloids), catecholamine administration, use of mechanical ventilation, body temperature, arterial blood gas analysis on admission, lactate level, hemoglobin level, creatinine level, presence of hemorrhagic shock (defined as at the transfusion of at least four units of packed red blood cells within $6 \mathrm{~h}$ ), TBI (at least one visible lesion on computed tomography), Injury Severity Score (ISS), in-hospital length of stay, and in-hospital mortality.

\section{Statistical methods}

Patients were divided into two groups of exposure a priori according to their initial $\mathrm{PaO}_{2}$ on hospital admission: normoxemia $\left(\mathrm{PaO}_{2} \quad 60-150 \mathrm{mmHg}\right)$ and hyperoxemia $\left(\mathrm{PaO}_{2} \geq 150 \mathrm{mmHg}\right)$. The $150 \mathrm{mmHg}$ cut-off was used as this has previously been done in 
an RCT on ICU patients [22], as well as in several observational studies [23-25].

Our primary aim was to assess the correlation between hyperoxemia on hospital admission and in-hospital mortality. Two pre-planned subgroup analyses on patients with an initial GCS $<8$ and mechanically ventilated patients were also planned.

Categorical variables are expressed as numbers with percentages (\%) and continuous variables as means with standard deviations (SD), or medians with interquartile ranges [IQR]. Characteristics were compared using a chi $^{2}$ test for categorical data and $t$ test or MannWhitney $U$ test for continuous data.

Since hyperoxemia is caused by exposure to high oxygen levels, the association between hyperoxemia and inhospital mortality was assessed using propensity score to reduce potential selection bias due to measured baseline covaries. The variables included in the model were chosen a priori by comparing pre-hospital variables and baseline characteristics between patients that died and survived to hospital discharge. Significant determinants of mortality were included.

The score was estimated using logistic regression, and the primary analyses were made using inverse probability of treatment weighting (IPTW).

To verify the robustness of the results, two sensitivity analyses were performed using a propensity score analysis with a matching method with a 1:1 ratio within a caliper of 0.05 standard deviation of the logit propensity score and a stratification on the quintiles of the propensity score. To account for missing data, analyses were conducted using multiple imputations by chained equations with 10 imputations obtained after 10 iterations [26]. A complete-case analysis was also performed to verify the results. The propensity scores came from 10 independent complete data sets and were averaged according to the "across approach" [27]. Balance in potentials confounders were assessed by standardized mean differences which came from a complete imputed data set [28]. A multivariate full model including factors used in the propensity score was also performed to verify the results of the propensity score.

Finally, several sensitivity analyses were performed. An analysis removing patients who died within $24 \mathrm{~h}$ of hospital admission was carried out to allow sufficient time for deleterious effects such as lung complications of oxygen to develop, and an analysis on patients with a GCS $<8$ as well as an analysis on intubated patients was done. Furthermore, other cutoffs for hyperoxemia were examined $\left(\mathrm{PaO}_{2} \geq 100 \mathrm{mmHg}\right.$ and $\left.\mathrm{PaO}_{2} \geq 200 \mathrm{mmHg}\right)$, and the $\mathrm{PaO}_{2} / \mathrm{FiO}_{2}$ was explored using the Berlin definition [29].

All tests were two-tailed, and the results were considered statistically significant when $p<0.05$. Analyses were performed using $\mathrm{R}$ statistical software [30].

\section{Results}

Of 6654 adult trauma patients with $\mathrm{PaO}_{2}$ values available in the database, 544 were excluded as they were withdrawn from life-sustaining therapy and 462 were excluded as they were hypoxemic on arrival, leaving 5912 patients for analysis (Fig. 1).

The median age was 39 years and the majority were males (Table 1). More than half of all patients had an ISS score above 15, and one third presented with TBI. The overall in-hospital mortality was $10 \%$.

On hospital admission, the median $\mathrm{PaO}_{2}$ of the entire cohort was $133 \mathrm{mmHg}: 3342$ (57\%) were normoxemic, and 2570 (43\%) were hyperoxemic. Numerous baseline characteristics were significantly different between normoxemic and hyperoxemic patients: a higher proportion of hyperoxemic patients were mechanically ventilated (a comparison of baseline characteristics between intubated and spontaneously breathing patients can be found in Additional file 2), they had lower prehospital GCS scores and more suffered from a TBI. On univariate analysis, the in-hospital mortality was higher for hyperoxemic patients $(12 \%$ versus $9 \%, p<0.0001)$ (Table 1).

In a propensity score model, patients were matched based upon significant determinants of mortality amongst the baseline characteristics (Table 2). The model revealed an inverse relationship between hyperoxemia and in-hospital mortality: mortality was significantly decreased in hyperoxemic patients compared to normoxemic patients (OR 0.59 [0.50-0.70], $p<0.0001)$ and hyperoxemia thus appeared as a protective factor. The accuracy of the model is presented in Fig. 2. Here, the balances in potentials confounders were also checked, and the absolute mean differences were all less than 5\% after using propensity score (IPTW and matching methods). The multivariate full model including factors used in propensity score verified the results of the propensity score (Additional file 3). A complete-case analysis presented very similar results (OR 0.60 [0.46-0.78], $p<0.0001$ ).

In a sensitivity analysis, where patients deceased within $24 \mathrm{~h}$ were excluded, the results remained statistically significant (OR 0.63 [0.52-0.76], $p<0.0001$ ) (Table 3).

Likewise, in our subgroup analysis on patients with a $\mathrm{GCS}<8$, mortality was also decreased in hyperoxemic patients (OR 0.69 [0.53-0.89], $p=0.005$ ). The same was true in a subgroup analysis on intubated patients (OR 0.62 [0.50-0.77], $p<0.0001$ ) (Table 3).

Furthermore, our sensitivity analyses also showed a beneficial effect on mortality using $\mathrm{PaO}_{2} / \mathrm{FiO}_{2} \geq 300$, and different cut-off levels for hyperoxemia $\left(\mathrm{PaO}_{2} \geq 100\right.$ $\mathrm{mmHg}$ and $\mathrm{PaO}_{2} \geq 200 \mathrm{mmHg}$ ) left our results largely unaltered (Table 3). 


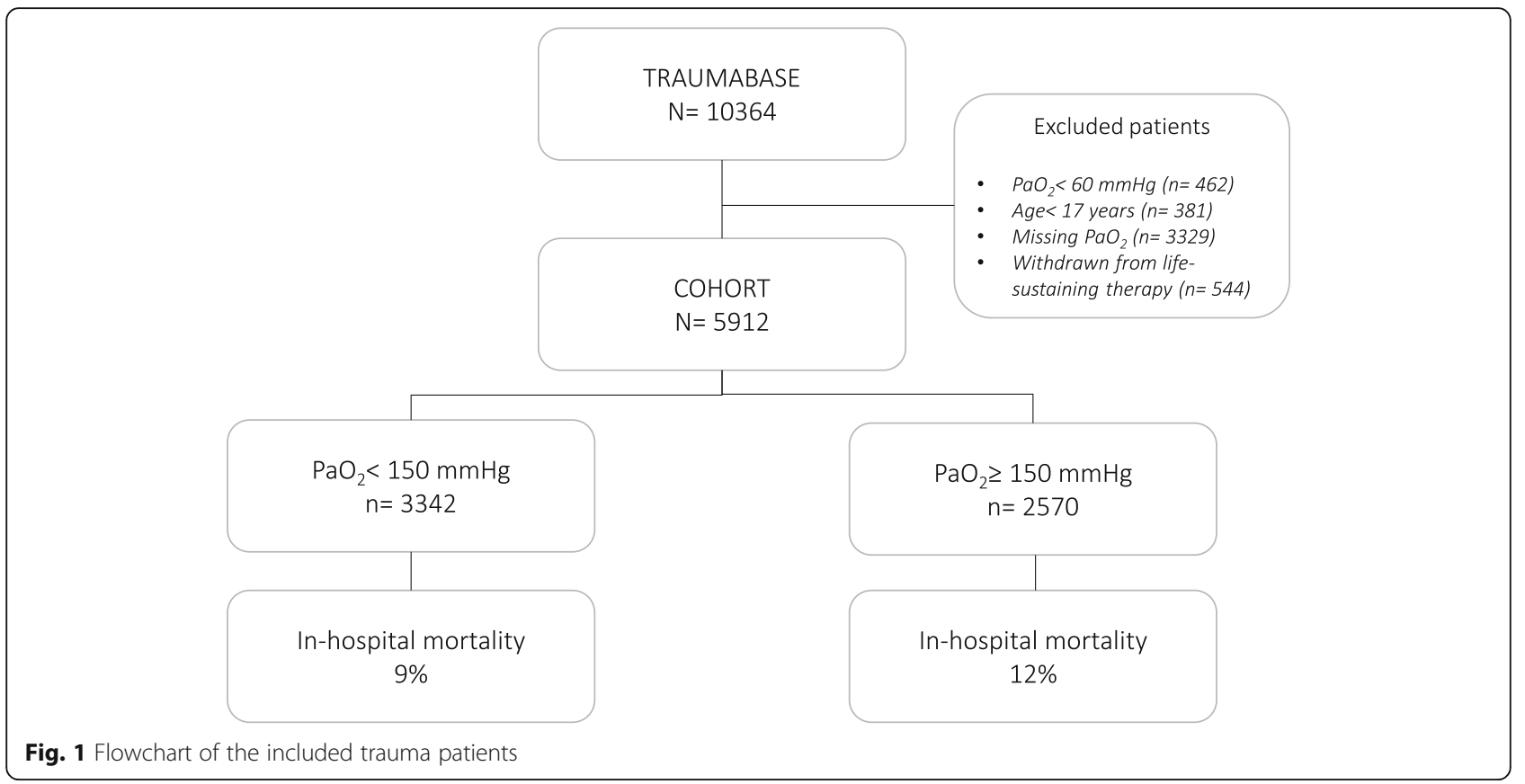

\section{Discussion}

In this large observational study of nearly 6000 trauma patients, we found hyperoxemia above $150 \mathrm{mmHg}$ on hospital admission to be independently associated with a significantly decreased in-hospital mortality compared to normoxemia. This result challenges our initial hypothesis. Our results were unaltered by a sensitivity analysis, where patients deceased within $24 \mathrm{~h}$ were excluded.

The beneficial effects of supplemental oxygen for the critically ill patient have remained undisputed for decades and have resulted in international guidelines on initial trauma management recommending high fractions of inspired oxygen. However, although it is suspected that hyperoxemia may be deleterious (due to increased oxidative stress, vasoconstriction, and potential hyperoxemic lung injury) [31], the evidence both in favor and against supplemental oxygen, and thus the risk of hyperoxemia, is almost non-existent in trauma patients [19].

Supplemental oxygen seems to possess a potential to rescue threatened neurons after brain injury or in the ischemic penumbra [32, 33], and it is known to prolong the safe apnea time [34]. Nevertheless, numerous physiologic arguments exist against liberal administration of oxygen in critically ill patients. For example, excess oxygen has been associated with the formation of reactive oxygen species which are detoxified in the mitochondria by a variety of antioxidants. Furthermore, acute states such as shock induce an increased production of reactive oxygen species worsening the imbalance between prooxidants and antioxidants [6].
In recent years, the optimal targets of both $\mathrm{SpO}_{2}$ and $\mathrm{PaO}_{2}$ have therefore been challenged in acutely ill patients. A large meta-analysis showed increased rates of mortality for patients with oxygen saturation $\left(\mathrm{SpO}_{2}\right)$ above $96 \%$ compared to $94-96 \%$ [11]. However, as the trial sequential analysis was driven primarily by a single large randomized trial [35], the authors were unable to exclude a small beneficial effect of liberal oxygen. Only one RCT on trauma patients was included, and here no effect of liberal oxygen was observed. Another metaanalysis on patients with cardiac arrest showed beneficial effects of oxygen intra-arrest while post-arrest arrest hyperoxemia was associated with increased mortality [36]. A recent systematic review found a higher all-cause mortality in ICU patient with hyperoxemia [25]; however, in subgroup analyses on patients with TBI and patients on mechanical ventilation, results were inconclusive.

In trauma patients, studies on liberal versus conservative oxygen approaches are sparse. To date, only two small RCTs have been done on patients with TBI, and here, one found difference between a liberal and restrictive oxygen approach on mortality [17], and the other found no differences in terms of neurological outcome [37]. Furthermore, the few retrospective studies available have shown inconsistent results: one recent large study showed no difference in in-hospital mortality between hyperoxemic and normoxemic trauma patients [18], others have shown a deleterious effect of hyperoxemia $[38,39]$, and yet two studies have found a strong relationship between hyperoxemia and better long-term, 
Table 1 Baseline characteristics of all included trauma patients including a comparison of norm- and hyperoxemic patients. Results are presented as medians with [interquartile ranges], numbers with (percentages), or as otherwise indicated

\begin{tabular}{|c|c|c|c|c|}
\hline & $\begin{array}{l}\text { All patients } \\
N=5912\end{array}$ & $\begin{array}{l}\text { Normoxemic } \\
60<\mathrm{PaO}_{2}<150 \mathrm{mmHg} \\
n=3342\end{array}$ & $\begin{array}{l}\text { Hyperoxemic } \\
\mathrm{PaO}_{2} \geq 150 \mathrm{mmHg} \\
n=2570\end{array}$ & $p$ value \\
\hline Age & $39[26-55]$ & 41 [17-96] & 36 [17-96] & $<0.0001$ \\
\hline Sex (female) & $1273(21.6)$ & $703(21.1)$ & $570(22.3)$ & 0.3 \\
\hline ASA-score > 1 & $1903(34.5)$ & $1168(37.0)$ & $735(31.1)$ & $<0.0001$ \\
\hline \multicolumn{5}{|l|}{ Mechanism of injury } \\
\hline Falls from height & $1368(21.5)$ & $747(22.4)$ & $521(20.3)$ & 0.089 \\
\hline Falls from standing & $240(4.1)$ & $132(4.0)$ & $108(4.2)$ & \\
\hline Vehicle incident/collision & $3339(56.5)$ & $1895(56.7)$ & $1444(56.2)$ & \\
\hline Shootings & $590(10.0)$ & $211(9.3)$ & $279(10.9)$ & \\
\hline Fight & $204(3.5)$ & $117(3.5)$ & $87(3.4)$ & \\
\hline Other & $270(4.6)$ & $139(4.2)$ & $131(5.1)$ & \\
\hline \multicolumn{5}{|l|}{ Site of injury } \\
\hline Head and neck & $2823(51.1)$ & $1461(46.9)$ & $1362(64.4)$ & $<0.0001$ \\
\hline Face & $1389(25.1)$ & $707(22.7)$ & $682(28.3)$ & $<0.0001$ \\
\hline Abdomen & $1833(33.2)$ & $1022(32.8)$ & $811(33.6)$ & 0.56 \\
\hline Chest & $2865(51.8)$ & $1647(52.9)$ & $1218(50.5)$ & 0.079 \\
\hline External & $924(16.7)$ & $533(17.1)$ & $391(16.2)$ & 0.39 \\
\hline Extremities & $3080(55.7)$ & $1684(54.1)$ & $1396(57.9)$ & 0.0055 \\
\hline Duration of prehospital care (minutes), median [IQR] & $70[48-100]$ & 79 [49-97] & $70[45-105]$ & 0.58 \\
\hline Prehospital systolic blood pressure (mmHg) & $127[110-141]$ & $130[0-256]$ & $124[0-230]$ & $<0.0001$ \\
\hline Prehospital heart rate (bpm) & 89 [75-105] & $88[0-170]$ & $76[0-155]$ & $<0.0001$ \\
\hline Prehospital intubation & $1840(31.7)$ & $651(19.9)$ & $1189(47.0)$ & $<0.0001$ \\
\hline Prehospital GCS score & 15 [11-15] & 15 [3-15] & 14 [3-15] & $<0.0001$ \\
\hline \multicolumn{5}{|l|}{ Values on hospital arrival } \\
\hline $\mathrm{pH}$ & $7.4[7.3-7.4]$ & $7.4[7.3-7.4]$ & $7.3[7.3-7.4]$ & $<0.0001$ \\
\hline $\mathrm{PaO}_{2}$ & 133 [93-216] & $97[81-117]$ & $230[186-308]$ & - \\
\hline $\mathrm{PCO}_{2}$ & $40[35-44]$ & $39[35-43]$ & $40[26-45]$ & $<0.0001$ \\
\hline Temperature $\left({ }^{\circ} \mathrm{C}\right)$ & $36.5[35.9-37.0]$ & $36.6[26.4-41.0]$ & $36.4[26.0-40]$ & $<0.0001$ \\
\hline Lactate $(\mathrm{mmol} / \mathrm{L})$ & $1.9[1.2-3.0]$ & $1.8[0.2-23.4]$ & $2[0.2-25]$ & $<0.0001$ \\
\hline Creatinine $(\mu \mathrm{mol} / \mathrm{L})$ & 77 [65-92] & $77[8-1004]$ & 77 [7-926] & 0.64 \\
\hline Hemoglobin (mmol/L) & $13[11.5-14.2]$ & $13.3[3.9-21.6]$ & $12.6[1.1-20.0]$ & $<0.0001$ \\
\hline Catecholamine administration & $815(14.3)$ & $322(10.0)$ & $493(19.9)$ & $<0.0001$ \\
\hline Fluid replacement & $500[250-1000]$ & $500[0-7000]$ & $750[0-5500]$ & $<0.0001$ \\
\hline ISS score & 16 [9-25] & $13[8-24]$ & 18 [10-27] & $<0.0001$ \\
\hline ISS score $>15$ & $2935(52.9)$ & $1433(45.9)$ & $1502(62.0)$ & $<0.0001$ \\
\hline Traumatic brain injury & $1836(31.6)$ & $824(25.1)$ & $1012(40.1)$ & $<0.0001$ \\
\hline Hemorrhagic shock & $545(9.4)$ & $202(6.2)$ & $343(13.6)$ & $<0.0001$ \\
\hline In-hospital mortality ${ }^{a}$ & $481(10.0)$ & $239(8.7)$ & $242(11.6)$ & $<0.0001$ \\
\hline Cause of death (available for 426 patients) & & & & $<0.01$ \\
\hline Hemorrhagic shock & $46(10.8)$ & $21(10.0)$ & $25(11.5)$ & \\
\hline Septic chock & $6(1.4)$ & $3(1.4)$ & $3(1.4)$ & \\
\hline Multi organ failure & $98(23.0)$ & $59(28.2)$ & 39 (18.0) & \\
\hline Brain death & $197(46.2)$ & $85(40.7)$ & $112(51.6)$ & \\
\hline
\end{tabular}


Table 1 Baseline characteristics of all included trauma patients including a comparison of norm- and hyperoxemic patients. Results are presented as medians with [interquartile ranges], numbers with (percentages), or as otherwise indicated (Continued)

\begin{tabular}{llll}
\hline & All patients & $\begin{array}{l}\text { Normoxemic } \\
\mathbf{6 0}<\mathrm{PaO}_{\mathbf{2}}<\mathbf{1 5 0} \mathbf{m m H g} \\
\boldsymbol{n}=\mathbf{3 3 4 2}\end{array}$ & $\begin{array}{l}\text { Hyperoxemic } \\
\mathbf{P a O}_{\mathbf{2}} \geq \mathbf{1 5 0} \mathbf{m m H g} \\
\boldsymbol{n}=\mathbf{2 5 7 0}\end{array}$ \\
\hline Traumatic brian injury & $\boldsymbol{N = 5 9 1 2}$ & $26(12.4)$ & $32(14.7)$ \\
Other & $58(13.6)$ & $15(7.1)$ & $6(2.8)$ \\
\hline
\end{tabular}

The provided pre-hospital vital signs are the first vital signs recorded on-scene

Abbreviations: ASA, American Society of Anesthesiologists; GCS, Glasgow Coma Scale score; ISS, Injury Severity Score; Hemorrhagic shock, defined as administration of at least four units of packed red blood cells within $6 \mathrm{~h}$; Fluid replacement, $\mathrm{mL}$ of colloids and/or crystalloids

${ }^{a}$ Missing in $18 \%$. Imputated in the propensity score analysis

functional, and cognitive outcomes $[24,40]$. As such the physiologic consequences of hyperoxemia on outcomes after TBI remain uncovered. In several studies, a decrease in cerebral perfusion of up to $30 \%$ has been observed in individuals exposed to hyperoxia [41-43], while other studies have suggested that hyperoxia aids in one of the cornerstones in treatment of traumatic brain injury: decreasing intracranial pressure [44-46]. Supplemental oxygen could also be beneficial in TBI by simply increasing the level of oxygen in the brain. In stroke patients, supplemental oxygen has been proposed to rescue threatened neurons, and thus the brain, from further deterioration [47]. Nonetheless, studies so far have failed to show an association between supplemental oxygen and improved physical function [35, 48]. Further research in larger cohorts should look into this to help uncover the induced pathways.

In accordance with several of the above studies, we found a clinical benefit of early hyperoxemia in the current study. Of note, however, all the latter studies focus solely on trauma patients with TBI, whereas we chose to include all trauma patients to present a broader and more pragmatic perspective, as isolated TBI may not always be evident in the acute phase. Nonetheless, in our subgroup analysis of patients with $\mathrm{GCS}<8$, our results were unchanged.

Table 2 Baseline differences amongst trauma patients that survived to hospital-discharge or died in-hospital. Results are presented as medians with [interquartile ranges], numbers with (percentages), or as otherwise indicated

\begin{tabular}{|c|c|c|c|}
\hline & \multicolumn{2}{|c|}{ In-hospital mortality } & \multirow[t]{2}{*}{$p$ value } \\
\hline & Survived & Deceased & \\
\hline Age & 37 [17-96] & 53 [17-96] & $<0.0001$ \\
\hline Sex (female) & $906(20.9)$ & $123(25.6)$ & 0.019 \\
\hline ASA-score $>1$ & $1328(32.2)$ & $223(32.8)$ & $<0.0001$ \\
\hline Prehospital systolic blood pressure (mmHg) & $128[0-237]$ & $129[0-237]$ & $<0.0001$ \\
\hline Prehospital heart rate (bpm) & $90[0-240]$ & $85[0-200]$ & 0.005 \\
\hline Prehospital intubation & $1190(27.8)$ & $365(77.3)$ & $<0.0001$ \\
\hline Prehospital GCS score & $15[3-15]$ & $4[3-15]$ & $<0.0001$ \\
\hline \multicolumn{4}{|l|}{ Values on hospital arrival } \\
\hline $\mathrm{PaO}_{2}$ & $131[60-812]$ & $151[60-609]$ & 0.011 \\
\hline $\mathrm{PaO}_{2} \geq 150 \mathrm{mmHg}$ & $1842(42.4)$ & $242(50.3)$ & 0.001 \\
\hline Temperature $\left({ }^{\circ} \mathrm{C}\right)$ & $36.5[26.4-40.5]$ & $35.5[30.0-41.0]$ & $<0.0001$ \\
\hline Lactate (mmol/L) & $1.9[0.2-24]$ & $3.5[0.4-24]$ & $<0.0001$ \\
\hline Creatinine $(\mu \mathrm{mol} / \mathrm{L})$ & $76(7-1001]$ & 94 [29-950] & $<0.0001$ \\
\hline Hemoglobin (mmol/L) & $13.1[1.1-21.6]$ & 11.4 [1.8-19] & $<0.0001$ \\
\hline Catecholamine administration & $461(10.9)$ & $223(48.9)$ & $<0.0001$ \\
\hline Fluid replacement & $500[0-6500]$ & $1000[0-5500]$ & $<0.0001$ \\
\hline ISS score & $14[9-24]$ & $29[25-41]$ & $<0.0001$ \\
\hline ISS score > 15 & $2024(48.7)$ & $417(90.7)$ & $<0.0001$ \\
\hline Traumatic brain injury & $1209(28.0)$ & $329(68.7)$ & $<0.0001$ \\
\hline Hemorrhagic shock & $320(7.4)$ & $148(30.8)$ & $<0.0001$ \\
\hline
\end{tabular}

Abbreviations: ASA, American Society of Anesthesiologists; GCS, Glasgow Coma Scale score; Hemorrhagic shock, defined as administration of at least four units of packed red blood cells within $6 \mathrm{~h}$; Fluid replacement, $\mathrm{mL}$ of colloids and/or crystalloids 


\begin{tabular}{|c|c|c|c|c|c|}
\hline Methods & & $\begin{array}{c}\mathrm{PaO}_{2}<150 \mathrm{mmHg} \\
\mathrm{n}=3342\end{array}$ & $\begin{array}{c}\mathrm{PaO}_{2} \geq 150 \mathrm{mmHg} \\
\mathrm{n}=2570\end{array}$ & OR $(95 \% \mathrm{Cl})$ & $\mathrm{p}$-value \\
\hline Without adjustment & & & & 1.31 [1.11-1.56] & 0.002 \\
\hline \multirow{3}{*}{ Propensity score } & IPTW & $291 / 3342$ & $286 / 2570$ & $0.59[0.50-0.70]$ & $<0.0001$ \\
\hline & 1:1 & $251 / 1976$ & $184 / 1976$ & $0.67[0.54-0.83]$ & 0.0003 \\
\hline & Stratified & $291 / 3342$ & $286 / 2570$ & $0.63[0.52-0.70]$ & $<0.0001$ \\
\hline
\end{tabular}

* Adjusted for sex, age, prehospital heart rate and systolic blood pressure, temperature, hemoglobin, lactate, airway management (intubated or not), TBI, initial GCS score, ASA $>1$ and the presence of hemorrhagic shock.

IPTW: Inverse probability of treatment weighting; 1:1: One-to-one matching; Stratified: Stratified approach

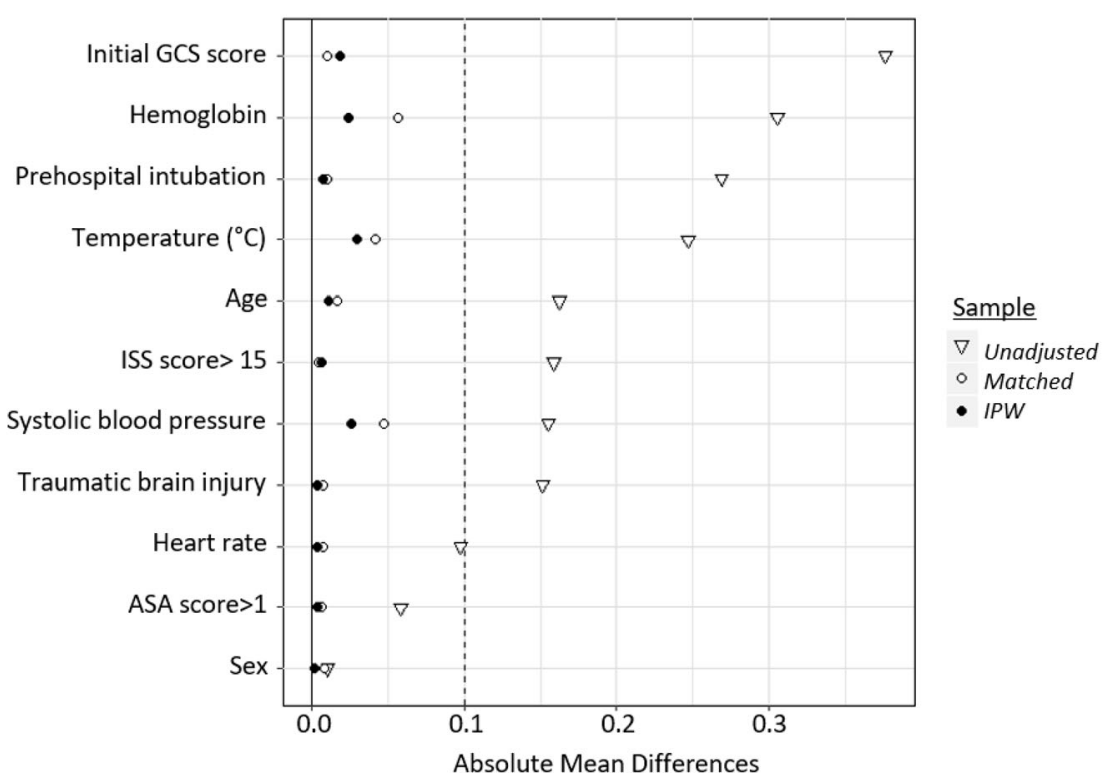

Fig. 2 In-hospital mortality in normoxemic $\left(60 \mathrm{mmHg}<\mathrm{PaO}_{2}<150 \mathrm{mmHg}\right)$ and hyperoxemic $\left(\mathrm{PaO}_{2} \geq 150 \mathrm{mmHg}\right)$ trauma patients using a propensity score model

Table 3 Sensitivity analyses. In-hospital mortality amongst subgroups of trauma patients (reference: Normoxemia)

\begin{tabular}{|c|c|c|c|}
\hline \multicolumn{4}{|l|}{ Subgroup } \\
\hline Survival beyond $24 \mathrm{~h}$ & Propensity score (IPTW) & $0.63[0.52-0.75]$ & $<0.0001$ \\
\hline \multirow[t]{2}{*}{ GCS $<8$} & Without adjustment & $0.55[0.43-0.71]$ & $<0.0001$ \\
\hline & Propensity score (IPTW) & $0.69[0.53-0.89]$ & 0.005 \\
\hline \multirow[t]{2}{*}{ Mechanically ventilated patients } & Without adjustment & $0.52[0.42-0.65]$ & $<0.0001$ \\
\hline & Propensity score (IPTW) & $0.62[0.50-0.77]$ & $<0.0001$ \\
\hline \multicolumn{4}{|l|}{ Cutoffs for hyperoxemia } \\
\hline \multirow[t]{2}{*}{$\mathrm{PaO}_{2} / \mathrm{FiO}_{2} \geq 300$} & Without adjustment & $0.32[0.27-0.38]$ & $<0.0001$ \\
\hline & Propensity score (IPTW) & $0.74[0.62-0.88]$ & 0.0007 \\
\hline \multirow[t]{2}{*}{$\mathrm{PaO}_{2} \geq 100 \mathrm{mmHg}$} & Without adjustment & $1.03[0.86-1.25]$ & 0.73 \\
\hline & Propensity score (IPTW) & $0.54[0.46-0.64]$ & $<0.0001$ \\
\hline \multirow[t]{2}{*}{$\mathrm{PaO}_{2} \geq 200 \mathrm{mmHg}$} & Without adjustment & $1.38[1.15-1.65]$ & 0.0005 \\
\hline & Propensity score (IPTW) & $0.72[0.59-0.87]$ & 0.0006 \\
\hline
\end{tabular}


The comparison of studies on hyperoxemia is difficult as some studies compare $\mathrm{SpO}_{2}$ values, others $\mathrm{FiO}_{2}$ values, and others $\mathrm{PaO}_{2}$ values. Besides, when utilizing the $\mathrm{PaO}_{2}$, there is no consensus on the arbitrarily predetermined $\mathrm{PaO}_{2}$ cut-off [25]. In the current study, we chose to use $150 \mathrm{mmHg}$ as the threshold for hyperoxemia as it presented a large percentage of our population (43\%), and in addition, this approach has been used previously [22-25]. Numerous other studies have chosen values above $300 \mathrm{mmHg}$ to present hyperoxemia, thereby considering values below $300 \mathrm{mmHg}$ as normoxemic, which appears problematic. Furthermore, many studies have used the worst $\mathrm{PaO}_{2}$ (the highest $\left.\mathrm{PaO}_{2}\right)$ as their exposure variable $[49,50]$. We chose to use the first $\mathrm{PaO}_{2}$ recorded at hospital admission to reflect the pre-hospital treatment. This has previously been done $[38,51]$. Finally, the exposure duration should also be taken into account. As such, the attempt to answer whether or not hyperoxemia is harmful-in any patient population-should always aim to consider the variable measured $\left(\mathrm{SpO}_{2}, \mathrm{PaO}_{2}\right.$ or $\left.\mathrm{FiO}_{2}\right)$, the concentration of the given variable, and the exposure duration.

Our results reflect the liberal use of pre-hospital oxygen administration of severe trauma patients, and we found a high percentage (43\%) of patients with hyperoxemia at hospital admission. Although the duration of hyperoxemia in our study must be assumed to be relatively short (mean prehospital time from trauma until admission of $70 \mathrm{~min}$ ), several studies have found that deleterious effects of hyperoxemia may occur already during the first hours of administration. For example, both human and animal data have shown development of lung injury after just a few hours of exposure to hyperoxemia [10, 22, 52]. Furthermore, prehospital supplemental oxygen administration for patients with myocardial infarction has been associated with increased myocardial injury and infarct size at 6 months [53], and in a recent study, an association between an even shorter exposure time to hyperoxia and mortality was found in mechanically ventilated patients in the emergency department [14].

Nevertheless, in a recent small single center observational study, authors found no impact on 30-day mortality in trauma patients with early hyperoxemia [54], and in our current study on trauma patients, we even found a significant association between hyperoxemia on admission and decreased mortality compared to normoxemia on admission. The threshold for potentially toxic concentrations and duration of administration of oxygen are poorly defined, and the mechanisms behind a favorable effect may, at least partly, be explained by hemodynamic stabilization during shock, improvement in tissue bed oxygenation in both peri-contusional and remote neuronal tissue, and more aerobic neural metabolic profiles
[55]. These could be some of the explanation behind a positive effect of short-term hyperoxemia in the current study along with the actual ability of the affected individual to increase their $\mathrm{PaO}_{2}$ as demonstrated in the $\mathrm{PaO}_{2} /$ $\mathrm{FiO}_{2}$ sensitivity analysis. Regarding the exact threshold, the current study also shows that this may point towards mild hyperoxemia being the most beneficial, as the beneficial effect seemed to decrease when a higher $\mathrm{PaO}_{2}$ was used to define hyperoxemia.

\section{Limitations}

The primary limitation of the current study lies within its retrospective design, where, for instance, missing data often is seen. In our study, in-hospital mortality was unfortunately missing in $18 \%$. Furthermore, the $\mathrm{PaO}_{2}$ value was also missing in a substantial proportion of patients, leaving these patients for exclusion. It is impossible to know whether these were missing completely at random or not. However, for a large proportion, they seem to be missing completely at random, as other results of an arterial blood gas were available. Nonetheless, the large number of included patients allowed not only the propensity score analysis to include all the necessary variables for corrections but also important subgroup analyses. One must, however, keep in mind that the risk of hidden confounders still exists. Furthermore, although the first $\mathrm{PaO}_{2}$ recorded at hospital admission partly represents the prehospital management, the median of several consecutive $\mathrm{PaO}_{2}$ 's may have provided a more accurate picture. Moreover, in contrast to some other retrospective studies, we chose not to include a comparison group of hypoxemic patients, as the deleterious effect of hypoxemia is well established. This allows a cleaner comparison to the randomized trials available, where randomization is aimed at normoxemia versus hyperoxemia, thus not including a hypoxemic group.

We chose in-hospital mortality as our primary outcome as this seemed to be the most patient centered outcome available in the database. However, in future studies, other outcomes such as lactate levels and catecholamine administration could be interesting to look at, to gain a deeper understanding of the resulting physiological changes with different $\mathrm{PaO}_{2}$ levels.

Finally, the results of this study are based upon the French pre-hospital system which is characterized by the presence of emergency physicians in the field. The characteristics of the patients and the nature of their initial management can therefore not easily be extrapolated to EMS systems in other countries. Our results must therefore be compared with other systems of prehospital care.

\section{Conclusion}

In the current study, we found early hyperoxemia in severe trauma patients to be associated with a reduced in- 
hospital mortality. This result may support systematic administration of oxygen in trauma patients during the initial management in the prehospital setting, but the retrospective nature of the study warrants its careful interpretation. The study calls for a randomized clinical trial to further investigate this association.

\section{Supplementary information}

Supplementary information accompanies this paper at https://doi.org/10. 1186/s13054-020-03274-x.

Additional file 1. Supplementary table on baseline characteristics for hypoxemic patients $\left(\mathrm{PaO}_{2}<60 \mathrm{mmHg}\right)$

Additional file 2. Supplementary table on baseline characteristics for intubated vs spontaneously breathing patients.

Additional file 3. Multivariate full model including factors used in propensity score

\section{Abbreviations}

ASA score: American Society of Anesthesiologists score; ED: Emergency department; $\mathrm{FiO}_{2}$ : High inspired concentrations of oxygen; GCS: Glasgow Coma Scale; ICU: Intensive care unit; IPTW: Inverse probability of treatment weighting; IQR: Interquartile ranges; $\mathrm{PaO}_{2}$ : Arterial oxygen partial pressure; RCT: Randomized controlled trials; SD: Standard deviations; SMUR: Service Mobile d'Urgence et de Réanimation; $\mathrm{SpO}_{2}$ : Oxygen saturation; TBI: Traumatic brain injury

\section{Acknowledgements}

Collaborating author names of the Traumabase ${ }^{\oplus}$ group:

\section{Romain Pirracchio}

Service d'Anesthésie-réanimation, Hôpital Européen Georges Pompidou, Université Paris Descartes, Paris, France

Anne Godier

Service d'Anesthésie-réanimation, Hôpital Européen Georges Pompidou, Université Paris Descartes, Paris, France

Anatole Harrois

Université Paris Sud, Université Paris Saclay, Department of Anesthesiology and Critical Care, Assistance Publique-Hôpitaux de Paris (AP-HP), Bicêtre Hôpitaux Universitaires Paris Sud, 78 rue du Général Leclerc, 94275 Le Kremlin Bicêtre, F-94275, Le Kremlin Bicêtre, France

\section{Thomas Geeraerts}

Anesthesiology and Critical Care Department, University Hospital of Toulouse, University Toulouse 3-Paul Sabatier, Toulouse, France Eric Meaudre

Department of Anesthesiology and Intensive Care, Military Hospital, Hôpital d'Instruction des Armées Sainte-Anne, France and Emergency department, Military Hospital, Hôpital d'Instruction des Armées Sainte-Anne, France Sylvain Ausse

Department of Anesthesiology and Critical Care, Percy military hospital, Clamart, France

Tobias Gauss

Department of Anesthesia and Critical Care, Beaujon Hospital, AP-HP, University of Paris, Paris, France

Alain Meyer

Unités de Réanimation Chirurgicale et de Surveillance Continue, Hôpitaux Universitaires de Strasbourg, Strasbourg, France

Sophie Hamada

Université paris Sud, Université Paris Saclay, Department of Anesthesiology and Critical Care, Assistance Publique-Hôpitaux de Paris (AP-HP), Bicêtre Hôpitaux Universitaires Paris Sud, 78 rue du Général Leclerc, 94275 Le Kremlin Bicêtre, F-94275, Le Kremlin Bicêtre, France

Arthur Neuschwander

Service d'Anesthésie-réanimation, Hôpital Européen Georges Pompidou, Université Paris Descartes, Paris, France

Fabrice Cook

Department of Anaesthesia and Intensive Care Medicine, Henri Mondor University Hospital, Creteil, France

\section{Helene Vinour}

Anaesthesiology and Critical Care Department, University Hospital of Toulouse, University Toulouse 3-Paul Sabatier, Toulouse, France Jean Luc Hanouz

Department of Anesthesiology and Critical Care Medicine, Pôle Réanimations Anesthésie SAMU, Caen University Hospital, Caen, France

Arnaud Foucrier

Department of Anesthesia and Critical Care, Beaujon Hospital, AP-HP University of Paris, Paris, France

Mathieu Boutonnet

Department of Anesthesiology and Critical Care, Percy military hospital, Clamart, France

Pascal Raclot

Reims University Hospital, Robert Debré Hospital, Intensive Care Unit, Reims, France

James Arthur

Sorbonne Université and Department of Anesthesiology and Critical Care,

AP-HP, Hôpitaux Universitaires Pitié-Salpêtrière

Nathalie Bruneau

Pôle d'Anesthésie-Réanimation, CHU de Lille, Lille, France

Jean Cotte

Department of Anesthesiology and intensive care, military hospital, Hôpital d'Instruction des Armées Sainte-Anne, France

Marc Leone

Department of Anesthesiology and Intensive Care Medicine, Aix-Marseille University, Assistance Publique Hôpitaux de Marseille, Hôpital Nord, Marseille, France

Gerard Audibert

Department of Anesthesiology and surgical Intensive Care, University Hospital of Nancy, Nancy, France

Others:

For ideas, input and constructive criticism

Jacob Steinmetz

Department of Anesthesia, Centre of Head and Orthopedics, Rigshospitalet, University of Copenhagen, Denmark

Lars S. Rasmussen

Department of Anesthesia, Centre of Head and Orthopedics, Rigshospitalet, University of Copenhagen, Denmark

\section{Authors' contributions}

All authors have contributed to the analysis design, manuscript conception and drafting, the statistical analysis, and/or editorial review. Individual contributions were as follows:

JSB: - Substantial contributions to the conception and design of the work and the acquisition, analysis, and interpretation of data for the work. Revising it critically for important intellectual content. • Final approval of the version to be published. - Agreement to be accountable for all aspects of the work in ensuring that questions related to the accuracy or integrity of any part of the work are appropriately investigated and resolved. PA: - Substantial contributions to the conception and design of the work and the acquisition, analysis, and interpretation of data for the work. Revising it critically for important intellectual content. - Final approval of the version to be published. - Agreement to be accountable for all aspects of the work in ensuring that questions related to the accuracy or integrity of any part of the work are appropriately investigated and resolved. MB: - Substantial contributions to the analysis and interpretation of data for the work. • Revising it critically for important intellectual content. • Final approval of the version to be published. - Agreement to be accountable for all aspects of the work in ensuring that questions related to the accuracy or integrity of any part of the work are appropriately investigated and resolved. JM: - Substantial contributions to the conception and design of the work and the acquisition, analysis, and interpretation of data for the work. Revising it critically for important intellectual content. • Final approval of the version to be published. - Agreement to be accountable for all aspects of the work in ensuring that questions related to the accuracy or integrity of any part of the work are appropriately investigated and resolved.

DG: - Substantial contributions to the acquisition and interpretation of data for the work. - Revising it critically for important intellectual content. • Final approval of the version to be published. - Agreement to be accountable for all aspects of the work in ensuring that questions related to the accuracy or integrity of any part of the work are appropriately investigated and resolved. 
MR: • Substantial contributions to the acquisition and interpretation of data for the work. - Revising it critically for important intellectual content. - Final approval of the version to be published. - Agreement to be accountable for all aspects of the work in ensuring that questions related to the accuracy or integrity of any part of the work are appropriately investigated and resolved. BC: • Substantial contributions to the acquisition and interpretation of data for the work. - Revising it critically for important intellectual content. - Final approval of the version to be published. - Agreement to be accountable for all aspects of the work in ensuring that questions related to the accuracy or integrity of any part of the work are appropriately investigated and resolved. GD: - Substantial contributions to the acquisition and interpretation of data for the work. - Revising it critically for important intellectual content. - Final approval of the version to be published. - Agreement to be accountable for all aspects of the work in ensuring that questions related to the accuracy or integrity of any part of the work are appropriately investigated and resolved. JP: - Substantial contributions to the acquisition and interpretation of data for the work. - Revising it critically for important intellectual content. • Final approval of the version to be published. - Agreement to be accountable for all aspects of the work in ensuring that questions related to the accuracy or integrity of any part of the work are appropriately investigated and resolved. PL: • Substantial contributions to the acquisition and interpretation of data for the work. - Revising it critically for important intellectual content. - Final approval of the version to be published. - Agreement to be accountable for all aspects of the work in ensuring that questions related to the accuracy or integrity of any part of the work are appropriately investigated and resolved. FL: - Substantial contributions to the acquisition and interpretation of data for the work. • Revising it critically for important intellectual content. • Final approval of the version to be published. - Agreement to be accountable for all aspects of the work in ensuring that questions related to the accuracy or integrity of any part of the work are appropriately investigated and resolved. CBQ: - Substantial contributions to the acquisition and interpretation of data for the work. • Revising it critically for important intellectual content. • Final approval of the version to be published. - Agreement to be accountable for all aspects of the work in ensuring that questions related to the accuracy or integrity of any part of the work are appropriately investigated and resolved. FA: - Substantial contributions to the conception and design of the work and the acquisition, analysis, and interpretation of data for the work. • Drafting the work. - Final approval of the version to be published. - Agreement to be accountable for all aspects of the work in ensuring that questions related to the accuracy or integrity of any part of the work are appropriately investigated and resolved.

CPB: - Substantial contributions to the acquisition and interpretation of data for the work. - Revising it critically for important intellectual content. • Final approval of the version to be published. - Agreement to be accountable for all aspects of the work in ensuring that questions related to the accuracy or integrity of any part of the work are appropriately investigated and resolved.

\section{Funding}

The Traumabase ${ }^{\circledast}$ has been sponsored by the Regional Health Agency of lle de France for 2014-2017.

\section{Availability of data and materials}

The datasets generated during and/or analyzed during the current study may be available from the corresponding author on reasonable request.

\section{Ethics approval and consent to participate}

The data come from the Traumabase ${ }^{\oplus}$. This registry obtained approval from the Advisory Committee for Information Processing in Health Research (CCTI RS, 11.305bis) and from the National Commission on Informatics and Liberties (CNIL, 911461), and the analysis meets the requirement of the local and national ethics committee (Comité de Protection des Personnes, Paris $\mathrm{VI})$.

\section{Consent for publication}

All authors have reviewed and approved the manuscript and are willing to attest to their qualifications as authors, disclose potential conflicts of interest, and release copyright should the manuscript be accepted for publication.

\section{Competing interests}

None.

\section{Author details}

1Urgences et Samu 93, AP-HP, Avicenne Hospital, Inserm U942, 93000 Bobigny, France. ${ }^{2}$ Department of Anesthesia, Section 4231, Centre of Head and Orthopedics, Rigshospitalet, University of Copenhagen, Juliane Maries Vej 10, DK-2100 Copenhagen, Denmark. ${ }^{3}$ Department of Anesthesia and Critical Care, Beaujon Hospital, AP-HP, University of Paris, Paris, France. ${ }^{4}$ URC CRC, Avicenne Hospital, Bobigny, France. ${ }^{5}$ Department of Anesthesia and Critical Care, CHU de Lille, Lille, France. ${ }^{6}$ Sorbonne Université, INSERM, UMRS1158 Neurophysiologie Respiratoire Expérimentale et Clinique; AP-HP Groupe Hospitalier Universitaire APHP-Sorbonne Université, site Pitié-Salpêtrière, Département d'Anesthésie Réanimation, F-75013 Paris, France. ${ }^{7}$ Surgical Intensive Care Unit, Georges Pompidou European Hospital, AP-HP, Paris, France. ${ }^{8}$ Department of Anesthesia and Critical Care, AP-HP, Bicêtre Hospital, Paris, France. ${ }^{9}$ Department of Anesthesia and Surgical Critical Care, Strasbourg University Hospital, Strasbourg, France. ${ }^{10}$ Department of Anesthesia, Percy Army Training Hospital, Paris, France. ${ }^{11}$ Department of Anesthesia and Critical Care, University Hospital of Reims, Reims, France. ${ }^{12}$ Service d'Anesthésie-réanimation, Hôpital Européen Georges Pompidou, Université Paris Descartes, Paris, France. ${ }^{13}$ Université Paris Sud, Université Paris Saclay, Department of Anesthesiology and Critical Care, Assistance Publique-Hôpitaux de Paris (AP-HP), Bicêtre Hôpitaux Universitaires Paris Sud, 78 rue du Général Leclerc, 94275 Le Kremlin Bicêtre, F-94275 Le Kremlin Bicêtre, France. ${ }^{14}$ Anesthesiology and Critical Care Department, University Hospital of Toulouse, University Toulouse 3-Paul Sabatier, Toulouse, France.

${ }^{15}$ Department of Anesthesiology and Intensive Care, Military Hospital, Hôpital $\mathrm{d}^{\prime}$ Instruction des Armées Sainte-Anne, Toulon, France. ${ }^{16}$ Emergency department, Military Hospital, Hôpital d'Instruction des Armées Sainte-Anne, Toulon, France. ${ }^{17}$ Department of Anesthesiology and Critical Care, Percy military hospital, Clamart, France. ${ }^{18}$ Unités de Réanimation Chirurgicale et de Surveillance Continue, Hôpitaux Universitaires de Strasbourg, Strasbourg, France. ${ }^{19}$ Department of Anaesthesia and Intensive Care Medicine, Henri Mondor University Hospital, Creteil, France. ${ }^{20}$ Anaesthesiology and Critical Care Department, University Hospital of Toulouse, University Toulouse 3-Paul Sabatier, Toulouse, France. ${ }^{21}$ Department of Anesthesiology and Critical Care Medicine, Pôle Réanimations Anesthésie SAMU, Caen University Hospital, Caen, France. ${ }^{22}$ Reims University Hospital, Robert Debré Hospital, Intensive Care Unit, Reims, France. ${ }^{23}$ Sorbonne Université and Department of Anesthesiology and Critical Care, AP-HP, Hôpitaux Universitaires Pitié-Salpêtrière, Paris, France. ${ }^{24}$ Pôle d'Anesthésie-Réanimation, CHU de Lille, Lille, France. ${ }^{25}$ Department of Anesthesiology and Intensive Care Medicine, Aix-Marseille University, Assistance Publique Hôpitaux de Marseille, Hôpital Nord, Marseille, France. ${ }^{26}$ Department of Anesthesiology and surgical Intensive Care, University Hospital of Nancy, Nancy, France.

\section{Received: 21 November 2019 Accepted: 4 September 2020} Published online: 12 October 2020

\section{References}

1. $\mathrm{WHO}$ | Injuries and violence: the facts. Available from: http://www.who.int/ violence_injury_prevention/key_facts/en/. [cited 2017 Aug 11].

2. Cost of Injury \& Calculators | WISQARS | Injury Center | CDC. 2018. Available from: https://www.cdc.gov/injury/wisqars/cost/index.html. [cited 2019 May 10].

3. American College of Surgeons. ATLS: Advanced Trauma Life Support for Doctors (Student Course Manual), 9th edition. 2012.

4. Mosby. PHTLS: Basic and Advanced Prehospital Trauma Life Support. 5 edn. 2003.

5. Cornet AD, Kooter AJ, Peters MJ, Smulders YM. The potential harm of oxygen therapy in medical emergencies. Crit Care. 2013;17:313.

6. Damiani E, Donati A, Girardis M. Oxygen in the critically ill: friend or foe? Curr Opin Anaesthesiol. 2018;31:129-35.

7. Nagato AC, Bezerra FS, Lanzetti M, Lopes AA, Silva MAS, Porto LC, et al. Time course of inflammation, oxidative stress and tissue damage induced by hyperoxia in mouse lungs. Int J Exp Pathol. 2012;93:269-78.

8. Schwingshackl A, Lopez B, Teng B, Luellen C, Lesage F, Belperio J, et al. Hyperoxia treatment of TREK-1/TREK-2/TRAAK-deficient mice is associated with a reduction in surfactant proteins. Am J Physiol Lung Cell Mol Physiol. 2017:313:L1030-46.

9. Aboab J, Jonson B, Kouatchet A, Taille S, Niklason L, Brochard L. Effect of inspired oxygen fraction on alveolar derecruitment in acute respiratory distress syndrome. Intensive Care Med. 2006;32:1979-86. 
10. Staehr-Rye AK, Meyhoff CS, Scheffenbichler FT, Vidal Melo MF, Gätke MR, Walsh $J$, et al. High intraoperative inspiratory oxygen fraction and risk of major respiratory complications. BJA Br J Anaesth. 2017;119:140-9.

11. Chu DK, Kim LH-Y, Young PJ, Zamiri N, Almenawer SA, Jaeschke R, et al. Mortality and morbidity in acutely ill adults treated with liberal versus conservative oxygen therapy (IOTA): a systematic review and meta-analysis. Lancet Lond Engl. 2018;391:1693-705.

12. You J, Fan X, Bi X, Xian Y, Xie D, Fan M, et al. Association between arterial hyperoxia and mortality in critically ill patients: a systematic review and meta-analysis. J Crit Care. 2018;47:260-8.

13. Helmerhorst HJ, Schultz MJ, van der Voort PH, Bosman RJ, Juffermans NP, de Jonge $E$, et al. Self-reported attitudes versus actual practice of oxygen therapy by ICU physicians and nurses. Ann Intensive Care. 2014;4:23.

14. Page D, Ablordeppey E, Wessman BT, Mohr NM, Trzeciak S, Kollef MH, et al. Emergency department hyperoxia is associated with increased mortality in mechanically ventilated patients: a cohort study. Crit Care Lond Engl. 2018;22:9.

15. Suzuki S, Eastwood GM, Peck L, Glassford NJ, Bellomo R. Current oxygen management in mechanically ventilated patients: a prospective observational cohort study. J Crit Care. 2013;28:647-54.

16. Helmerhorst HJF, Schultz MJ, van der Voort PHJ, Bosman RJ, Juffermans NP, de Wilde RBP, et al. Effectiveness and clinical outcomes of a two-step implementation of conservative oxygenation targets in critically ill patients: a before and after trial. Crit Care Med. 2016;44:554-63.

17. Taher A, Pilehvari Z, Poorolajal J, Aghajanloo M. Effects of normobaric hyperoxia in traumatic brain injury: a randomized controlled clinical trial. Trauma Mon. 2016;21:e26772

18. Ó Briain D, Nickson C, Pilcher DV, Udy AA. Early hyperoxia in patients with traumatic brain injury admitted to intensive care in Australia and New Zealand: a retrospective multicenter cohort study. Neurocrit Care. 2018;29:443-51.

19. Eskesen TG, Baekgaard JS, Steinmetz J, Rasmussen LS. Initial use of supplementary oxygen for trauma patients: a systematic review. BMJ Open. 2018;8:e020880.

20. von Elm E, Altman DG, Egger M, Pocock SJ, Gøtzsche PC, Vandenbroucke JP, et al. The Strengthening the Reporting of Observational Studies in Epidemiology (STROBE) statement: guidelines for reporting observational studies. Int J Surg Lond Engl. 2014;12:1495-9.

21. Hamada SR, Gauss T, Duchateau F-X, Truchot J, Harrois A, Raux M, et al. Evaluation of the performance of French physician-staffed emergency medical service in the triage of major trauma patients. J Trauma Acute Care Surg. 2014;76:1476-83.

22. Girardis M, Busani S, Damiani E, Donati A, Rinaldi L, Marudi A, et al. Effect of conservative vs conventional oxygen therapy on mortality among patients in an intensive care unit: the oxygen-ICU randomized clinical trial. JAMA. 2016:316:1583-9.

23. Jouffroy R, Saade A, Saint Martin LC, Philippe P, Carli P, Vivien B. Prognosis value of partial arterial oxygen pressure in patients with septic shock subjected to pre-hospital invasive ventilation. Am J Emerg Med. 2019;37:56-60.

24. Alali AS, Temkin N, Vavilala MS, et al. Matching early arterial oxygenation to long-term outcome in severe traumatic brain injury: target values. $J$ Neurosurg. 2019;132(2):537-44. https://doi.org/10.3171/2018.10.JNS18964.

25. Ni Y-N, Wang Y-M, Liang B-M, Liang Z-A. The effect of hyperoxia on mortality in critically ill patients: a systematic review and meta analysis. BMC Pulm Med. 2019;19:53.

26. White IR, Royston P, Wood AM. Multiple imputation using chained equations: issues and guidance for practice. Stat Med. 2011;30:377-99.

27. Mitra R, Reiter JP. A comparison of two methods of estimating propensity scores after multiple imputation. Stat Methods Med Res. 2016;25:188-204.

28. Austin PC. An introduction to propensity score methods for reducing the effects of confounding in observational studies. Multivar Behav Res. 2011;46:399-424.

29. Definition Task Force ARDS, Ranieri VM, Rubenfeld GD, Thompson BT,

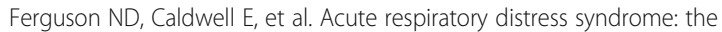
Berlin Definition. JAMA. 2012;307:2526-33.

30. R Foundation for Statistical Computing, Vienna, Austria. R Core Team. R: A language and environment for statistical computing. Vienna: R Foundation for Statistical Computing; 2016. Available from: https://www.R-project.org/.

31. Asfar $P$, Singer $M$, Radermacher $P$. Understanding the benefits and harms of oxygen therapy. Intensive Care Med. 2015;41:1118-21.

32. Pountain SJ, Roffe C. Does routine oxygen supplementation in patients with acute stroke improve outcome? BMJ. 2012;345:e6976.

33. Michalski D, Härtig W, Schneider D, Hobohm C. Use of normobaric and hyperbaric oxygen in acute focal cerebral ischemia - a preclinical and clinical review. Acta Neurol Scand. 2011;123:85-97.
34. Kelly C. Oxygen therapy: time to move on? Ther Adv Respir Dis. 2014;8:191-9.

35. Roffe C, Nevatte T, Sim J, Bishop J, Ives N, Ferdinand P, et al. Effect of routine low-dose oxygen supplementation on death and disability in adults with acute stroke: the stroke oxygen study randomized clinical trial. JAMA. 2017;318:1125-35

36. Patel JK, Kataya A, Parikh PB. Association between intra- and post-arrest hyperoxia on mortality in adults with cardiac arrest: a systematic review and meta-analysis. Resuscitation. 2018;127:83-8.

37. Lång M, Skrifvars MB, Siironen J, Tanskanen P, Ala-Peijari M, Koivisto T, et al. A pilot study of hyperoxemia on neurological injury, inflammation and oxidative stress. Acta Anaesthesiol Scand. 2018;62:801-10.

38. Davis DP, Meade W, Sise MJ, Kennedy F, Simon F, Tominaga G, et al. Both hypoxemia and extreme hyperoxemia may be detrimental in patients with severe traumatic brain injury. J Neurotrauma. 2009;26:2217-23.

39. Rincon F, Kang J, Vibbert M, Urtecho J, Athar MK, Jallo J. Significance of arterial hyperoxia and relationship with case fatality in traumatic brain injury: a multicentre cohort study. J Neurol Neurosurg Psychiatry. 2014;85:799-805.

40. Asher SR, Curry P, Sharma D, Wang J, O'Keefe GE, Daniel-Johnson J, et al. Survival advantage and $\mathrm{PaO} 2$ threshold in severe traumatic brain injury. J Neurosurg Anesthesiol. 2013;25:168-73.

41. Watson NA, Beards SC, Altaf N, Kassner A, Jackson A. The effect of hyperoxia on cerebral blood flow: a study in healthy volunteers using magnetic resonance phase-contrast angiography. Eur J Anaesthesiol. 2000;17:152-9.

42. Bulte DP, Chiarelli PA, Wise RG, Jezzard P. Cerebral perfusion response to hyperoxia. J Cereb Blood Flow Metab. 2007;27:69-75.

43. Borzage MT, Bush AM, Choi S, Nederveen AJ, Václavů L, Coates TD, et al. Predictors of cerebral blood flow in patients with and without anemia. J Appl Physiol (1985). 2016;120:976-81.

44. Tolias CM, Reinert M, Seiler R, Gilman C, Scharf A, Bullock MR. Normobaric hyperoxia--induced improvement in cerebral metabolism and reduction in intracranial pressure in patients with severe head injury: a prospective historical cohort-matched study. J Neurosurg. 2004;101:435-44.

45. Reinert M, Barth A, Rothen HU, Schaller B, Takala J, Seiler RW. Effects of cerebral perfusion pressure and increased fraction of inspired oxygen on brain tissue oxygen, lactate and glucose in patients with severe head injury. Acta Neurochir (Wien). 2003;145:341-9 discussion 349-350.

46. Rockswold SB, Rockswold GL, Zaun DA, Liu J. A prospective, randomized phase II clinical trial to evaluate the effect of combined hyperbaric and normobaric hyperoxia on cerebral metabolism, intracranial pressure, oxygen toxicity, and clinical outcome in severe traumatic brain injury. J Neurosurg. 2013:118:1317-28.

47. Singhal AB. Oxygen therapy in stroke: past, present, and future. Int J Stroke. 2006:1:191-200.

48. Rønning OM, Guldvog B. Should stroke victims routinely receive supplemental oxygen? A quasi-randomized controlled trial. Stroke. 1999;30:2033-7.

49. Helmerhorst HJF, Roos-Blom M-J, van Westerloo DJ, de Jonge E. Association between arterial hyperoxia and outcome in subsets of critical illness: a systematic review, meta-analysis, and meta-regression of cohort studies. Crit Care Med. 2015:43:1508-19.

50. Helmerhorst HJF, Arts DL, Schultz MJ, van der Voort PHJ, Abu-Hanna A, de Jonge $E$, et al. Metrics of arterial hyperoxia and associated outcomes in critical care. Crit Care Med. 2017;45:187-95.

51. Kilgannon JH, Jones AE, Parrillo JE, Dellinger RP, Milcarek B, Hunter $K$, et al. Relationship between supranormal oxygen tension and outcome after resuscitation from cardiac arrest. Circulation. 2011;123:2717-22.

52. Andrade PV, dos Santos JM, Silva HCA, Wilbert DD, Cavassani SS, OliveiraJúnior IS. Influence of hyperoxia and mechanical ventilation in lung inflammation and diaphragm function in aged versus adult rats. Inflammation. 2014;37:486-94.

53. Dion S, Karen S, Stephen B, Ziad N, Michael S, Bray Janet E, et al. Air versus oxygen in ST-segment-elevation myocardial infarction. Circulation. 2015;131: 2143-50.

54. Harpsø M, Granfeldt A, Løfgren B, Deakin CD. No effect of hyperoxia on outcome following major trauma. Open Access Emerg Med. 2019;11:57-63.

55. Bitterman H. Bench-to-bedside review: oxygen as a drug. Crit Care Lond Engl. 2009;13:205.

\section{Publisher's Note}

Springer Nature remains neutral with regard to jurisdictional claims in published maps and institutional affiliations. 